\title{
Stage IIIB Inflammatory Breast Carcinoma
}

National Cancer Institute

\section{Source}

National Cancer Institute. Stage IIIB Inflammatory Breast Carcinoma. NCI Thesaurus. Code C9246.

Inflammatory breast carcinoma is classified as AJCC Stage IIIB (T4d) unless other criteria indicate more advanced staging. 